\title{
Trabalhonecessário
}

Issn: 1808 - 799X

ano 14 , número $23-2016$

\section{REFORMA UNIVERSITÁRIA NO GOVERNO LULA: O QUE QUERIAM OS INDUSTRIAIS?}

Allan Kenji Seki ${ }^{1}$

Olinda Evangelista²

\section{Introdução}

O exame por nós empreendido de documentos do empresariado industrial, organizado na Confederação Nacional da Indústria (CNI), Serviço Social da Indústria (SESI), Instituto Euvaldo Lodi (IEL) e Serviço Nacional de Aprendizagem Industrial (SENAI), entre 2003 e 2010, teve em vista contribuir para a compreensão do sentido do projeto de reforma universitária defendido pelos industriais no período correspondente aos dois mandatos do Governo Lula (2003-2010) ${ }^{3}$.

Os modos de operação de uma parte significativa da burguesia interna, associada ao capital internacional, nas políticas educacionais públicas para a referida reforma sofreram alterações importantes após 2005, relacionadas às determinações gerais do capital articuladas a demandas de inovação e produtividade industrial. A mudança de interesses materiais resultou numa concepção antiuniversitária e na descaracterização do sentido amplo e público da formação universitária no país.

\footnotetext{
${ }^{1}$ Mestre em Educação pela Universidade Federal de Santa Catarina (UFSC), Doutorando em Educação na UFSC e Professor Substituto no Curso de Pedagogia na mesma Instituição. Pesquisador do Grupo de Estudos sobre Política Educacional e Trabalho (GEPETO). E-mail: allanknj@gmail.com

2 Mestre e Doutora em Educação pela Pontifícia Universidade Católica de São Paulo (PUC/SP). Professora aposentada da UFSC e voluntária no Programa de Pós-Graduação em Educação da UFSC (PPGE/UFSC). Bolsista produtividade CNPq. Pesquisadora do Grupo de Estudos sobre Política Educacional e Trabalho (GEPETO). E-mail: olindaevangelista35@hotmail.com.

${ }^{3}$ Este artigo deriva de dissertação de mestrado (SEKI, 2014) defendida no PPGE/UFSC.
} 


\section{Trabalhonecessário}

Issn: 1808 - 799X

ano 14, número $23-2016$

Nossa análise evidencia que as bases pedagógicas do projeto de reforma universitária dos industriais para as universidades brasileiras sustentam-se em dois eixos principais: a ideia de sociedade do conhecimento e a Teoria do Capital Humano. Tais eixos constituem os fundamentos de um discurso ideológico que procura obliterar a realidade do mundo do trabalho e criar, ao mesmo tempo, um sistema de identificações simbólicas voltado aos trabalhadores.

\section{A posição dos industriais até 2005}

Ao longo dos dois mandatos do Governo Lula (2003-2010), as propostas dos industriais (CNI, SESI, SENAI, IEL) para a reforma universitária brasileira não foram homogêneas. Produziram-se deslocamentos substantivos em suas propostas, necessariamente relacionados às determinações gerais do capital nesse período. Seki (2014, p. 130) afirma que

Até meados de 2005, os empresários da indústria defendiam que as universidades públicas deveriam voltar suas atividades para os interesses dos setores produtivos, o que implicava, por um lado, mudanças estruturais na formação de grandes contingentes de força de trabalho e, por outro, o aprofundamento das políticas de financiamento e avaliação das pesquisas científicas, reorientando-as para a inovação e a produtividade da indústria.

Propugnava-se uma integração harmoniosa entre as esferas pública e privada, com a flexibilização dos cursos e dos métodos pedagógicos das universidades, de modo a permitir sua massificação nas áreas tecnológicas, especialmente as que justificassem seus investimentos com maiores retornos para a formação de força de trabalho e pesquisas aplicadas. Até meados de 2004 e 2005, empresários da indústria demonstraram um descontentamento relativo com as instituições de ensino superior (IES) privadas: 


\section{Trabalhonecessário}

Issn: 1808 - 799X

ano 14 , número $23-2016$

De um lado reduziu-se sensivelmente a expansão do Sistema de Educação Superior Público, sobretudo o subsistema de maior tamanho, o federal, designado pelo conjunto das instituições Federais de Ensino Superior - IFES. De outro, sobretudo nas funções da Educação, as matrículas nas instituições particulares de educação superior passaram a ser majoritárias, apresentando, porém, graves deficiências qualitativas. Esses fatores evidenciaram o desequilíbrio do sistema de educação superior no Brasil e sua inadequação às reais necessidades do país. (CNI, 2004, p. 5)

Rodrigues (2007, p. 57) entende que isso se justificaria porque as IES privadas não se encontravam em condições de atender sequer a formação de baixa qualidade demandada pelo empresariado:

A indústria não escolheu buscar parceria com as empresas de educação superior, ou seja, torná-las alvo da "verdadeira revolução educacional", pelo simples motivo que as IES privadas não são capazes de responder às demandas da indústria, posto que apresentam "graves deficiências qualitativas". Assim, é bastante curioso perceber que a fração industrial da burguesia não confia no ensino-mercadoria, tampouco no conhecimento-mercadoria, produzidos pela nova burguesia de serviços.

Esse posicionamento crítico talvez explique a preservação, pelos industriais (CNI, 2004), da gratuidade no que diz respeito ao ensino de graduação nas universidades públicas. Contudo, exigiam, em contrapartida, a completa remodelação do seu papel em direção ao ensino flexível e à certificação em massa de "competências". O que os empresários industriais propunham não era outra coisa, senão 0 absoluto empresariamento das universidades públicas, tanto pela incorporação dos paradigmas de gestão e avaliação de resultados próprios das empresas privadas, como pela venda direta de resultados de pesquisas aplicadas. No segundo aspecto, percebe-se a importância atribuída à privatização do conhecimento por meio de patentes no campo da inovação ou mesmo à prestação de serviços de consultoria e permeabilidade entre os quadros funcionais de universidades públicas com as empresas. Rodrigues (2007, p. 49) concluiu que "A CNI, portanto, não 


\section{Trabalhonecessário}

Issn: 1808 - 799X

ano 14 , número $23-2016$

[defendia] a privatização das universidades públicas da mesma forma que ocorreu com as empresas estatais, mas [pretendia] atrelar as IES à lógica e aos propósitos do Capital".

Entre 2008 e 2010 os empresários do capital industrial ainda demonstravam interesse em formar uma parcela de seus trabalhadores nas universidades públicas federais, bem como constituir um contingente da força de trabalho que engrossasse 0 exército industrial de reserva com nível superior, de modo a regular as pressões salariais e o avanço de lutas por redução das jornadas de trabalho. Ademais, estava em jogo a obtenção de consenso social em torno de seus projetos universitários com as frações médias da classe trabalhadora que veem na educação um meio de aspiração pela melhora de suas condições de venda de sua força de trabalho. A CNI tinha clareza acerca de seus interesses na reforma da Universidade pública:

A contribuição da indústria para a reforma da Educação Superior vai além do atendimento à solicitação do Ministério da Educação. Sua presença e seu compromisso com esse nível de ensino justificam-se pelo seu tríplice papel: como usuário, pois recebe o conhecimento e os recursos humanos formados pela universidade. Como colaborador, pois propicia a complementação da formação, integrando empresauniversidade, principalmente por meio de ações de cooperação voltadas à inovação tecnológica promovidas pelo Instituto Euvaldo Lodi - IEL. Como ofertante, pois já ocupa espaços não devidamente preenchidos na educação superior de cunho tecnológico por meio do SENAI e na educação corporativa por meio do SESI. (CNI, 2004, p. 10)

Os industriais, em certa medida, também são ofertantes e se reconhecem como tais; até a publicação do documento Contribuição da Indústria para a reforma da educação superior (CNI, 2004) seu interesse maior é claramente desmontar o modelo universitário público para implementar uma formação aligeirada e flexível. Completava seu intuito a orientação para a certificação de trabalhadores em larga quantidade nos setores que o mercado de trabalho demandava e estritamente no domínio das 


\section{Trabalhonecessário}

Issn: 1808 - 799X

ano 14, número $23-2016$

técnicas exigidas em cada momento - evidenciando uma pedagogia toyotista ${ }^{4}$. Após esse documento (CNI, 2004), as propostas modificam-se gradualmente em favor de uma posição privatista - no sentido estrito do termo.

\section{O deslocamento de interesses dos industriais}

Ainda que no documento Contribuição da Indústria à reforma universitária: análise da segunda versão do anteprojeto de lei da reforma universitária (CNI, 2005) o discurso dos industriais invista contra as bases do modelo universitário humboldtiano, nele apresentam-se os primeiros e cruciais deslocamentos operados no projeto do empresariado industrial. Indica-se o Processo de Bolonha (PORTUGAL, 2016) como modelo a ser seguido no Brasil e, simultaneamente, desaparecem não só as críticas às IES privadas, como aparecem os argumentos favoráveis à abertura dessas instituições ao capital internacional e à restrição do papel do Estado na Educação Superior à avaliação, regulação e ao credenciamento das IES. Esse deslocamento vem acompanhado de outra estratégia política - a supressão da educação superior do rol das prioridades educacionais da CNI -, cujos desdobramentos rebaterão tanto nas intervenções empresariais, quanto nas políticas educacionais do Governo Lula.

De 2008 até 2010 a Universidade pública deixa de ser tematizada, na mesma medida em que inversamente cresce o papel ocupado pela educação profissional e tecnológica nos documentos dos industriais, além de maior atenção dada à Educação Básica. Destarte, sustenta-se ainda o desmonte da universidade em seu sentido amplo de formação tendo em vista readequar suas bases pedagógicas, alterar

\footnotetext{
${ }^{4}$ Outra expressão desse fenômeno nas universidades brasileiras é tratada na pesquisa de mestrado de Aline de Souza Mandeli, Fábrica de professores em nível superior: a Universidade Aberta do Brasil (2003-2014), defendida no PPGE-UFSC (MANDELI, 2014).
} 


\section{Trabalhonecessário}

Issn: 1808 - 799X

ano 14, número $23-2016$

substancialmente seu papel e alargar sua espinha dorsal para expandir suas fronteiras de mercadorização.

Em 2010, no documento $A$ indústria e o Brasil: uma agenda para crescer mais e melhor (CNI, 2010), ocorre, entretanto, um posicionamento mais claro. Não apenas os empresários diminuem a importância das universidades em suas propostas como expressam formalmente que a educação superior universitária não é mais a prioridade e, mais que isso, propõem "[...] a eliminação da educação superior pública e gratuita, seguida pelo repasse dos recursos poupados para a educação básica" (CNI, 2010, p. 160). Claro, seria uma questão de "justiça social": o investimento por aluno na Educação Superior é mais de seis vezes maior que na Educação Básica. Ademais,

Da forma como está desenhado, o sistema educacional brasileiro favorece a população de renda mais elevada, o que só faz aumentar a desigualdade educacional e social do País. [...] As deficiências do sistema público da educação básica fazem com que a maioria dos alunos das universidades públicas seja oriunda dos extratos mais elevados de renda, que frequentaram escolas particulares e de melhor qualificação. (CNI, 2010, p. 160-161)

E completa:

Para facilitar a entrada de alunos de baixa renda nas instituições de educação superior, é preciso melhorar a educação básica pública. E, além disso, expandir o sistema de bolsas e crédito educativo que leve em conta a renda e, principalmente, o desempenho escolar do aluno, premiando o mérito e o esforço de cada um. Assim, ela proverá uma educação de qualidade e foco, direcionando sua grade de cursos e respectivas ementas para as demandas do mercado $e$ as necessidades do país. (CNI, 2010, p. 161)

É perceptível como os empresários industriais modificaram suas posições ao longo do governo Lula. Em cada novo documento expressa-se o sentido estrito da privatização do ensino superior público - sobretudo o federal - até a defesa de sua completa eliminação.

Uma hipótese forte para compreender o sentido desse deslocamento no projeto dos industriais é que, em grande parte, seus interesses foram atendidos pelas 


\section{Trabalhonecessário}

Issn: 1808 - 799X

ano 14, número $23-2016$

políticas do Governo Federal. Alguns autores (RODRIGUES, 2007; DE PAULA, 2008) evidenciaram o processo de incorporação ativa das demandas educacionais dos industriais e de outras frações do capital nas políticas levadas a cabo pelo Partido dos Trabalhadores (PT) nesse período. Em particular, De Paula (2008) demonstra que o Programa de Apoio a Planos de Reestruturação e Expansão das Universidades Federais (REUNI) atendeu diretamente os interesses do capital industrial, assim como o daquele capital que a autora denomina como nova burguesia de serviços educacionais. Essa hipótese incorporada em torno de um consenso social no âmbito do Estado ampliado (GRAMSCI, 1978) explicaria, ao menos em parte, o deslocamento gradual das contribuições da indústria para as reformas educacionais de Lula para novos pontos em disputa - por isso a ênfase da indústria em sua ideia-força de 2010 (CNI, 2010): a prioridade é a Educação Básica.

\section{Interesses industriais em jogo}

Sem a pretensão de esgotar as possibilidades de explicar esse processo, tratamos de algumas questões que podem abrir campos de discussão para apreendermos a complexidade do fenômeno da associatividade burguesa e sua atividade política no Aparelho de Estado. Entre elas consideramos ser importante compreender três blocos de interesses dos industriais nas universidades públicas: a) a formação de força de trabalho especialmente vinculada às áreas técnicas $e$ tecnológicas; b) a prestação de serviços, consultorias, desenvolvimento de produtos e inovações tecnológicas e c) a sustentação de seus interesses mercantis como prestadores de educação superior.

\section{A formação de força de trabalho}




\section{Trabalhonecessário}

Issn: 1808 - 799X

ano 14, número $23-2016$

A formação sugerida, flexível e fabril, deveria constituir amplo exército industrial de reserva, sobretudo de engenheiros, como forma de diminuir as pressões nos salários nas indústrias, uma vez que a rápida expansão de setores industriais - como o da construção civil $^{5}$, impulsionada pelo fluxo de produtos primários no mercado mundial - teria gerado mais postos de trabalhos em grandes obras e operações, diminuído o exército industrial de reserva e, por isso mesmo, criado maior pressão sobre os salários. O documento Engenharia para o desenvolvimento (2010), publicado pela CNI, SENAI e Pontifícia Universidade Católica do Rio de Janeiro (PUC-Rio) ${ }^{6}$, trata da formação de uma nova consciência na matriz de formação profissional brasileira e do Programa iNOVA Engenharia7 ${ }^{7}$ (SENAI; IEL, 2006) e Programa Brasileiro de Aceleração da Engenharia - BRASILTEC (FORMIGA; CARMO, 2010), demonstrando a importância atribuída à formação de sua força de trabalho ${ }^{8}$. Ao longo dos oito anos de governo de Lula, a indústria explicitou sua insatisfação e "ressentimento" (CNI, 2004) com o fato de que as universidades públicas formassem nas áreas humanas. Isso evidenciaria a inversão de prioridades que atravancava o desenvolvimento do país. Essa tônica foi gradualmente diminuindo após 2007 - ano em que, não se pode perder de vista, foi implementado o REUNI (LÉDA; MANCEBO, 2009; GREGÓRIO, 2012)9.

\footnotetext{
${ }^{5}$ Nas séries de publicações mensais Sondagem Industrial e Sondagem Industrial da Construção, a indústria da construção civil e correlacionadas é o setor desse capital que mais reclama falta de trabalhadores qualificados.

${ }^{6}$ Esse documento de 216 páginas não parece ter sido analisado na área da Educação segundo as bases de dados consultadas (Google Scholar e Scielo, no período entre 2003-2010).

${ }^{7}$ No documento avalia-se a situação dos cursos de Engenharia em 17 instituições públicas e privadas do país. Propõe-se políticas e ações para promover a modernização do ensino, uma vez que a atividade é considerada essencial para o processo de inovação tecnológica (SENAI; IEL, 2006).

${ }^{8}$ Esse sentido foi reiterado repetidas vezes na documentação dos empresários industriais (CNI, 2004, 2005, 2007). Em 30 de julho de 2014, no encontro da CNI com os candidatos à presidência da República em Brasília (DF), o seu representante expressou sua indignação com o fato de que o Brasil forme apenas 40 mil engenheiros por ano.

${ }^{9} \mathrm{O}$ trabalho de pesquisa em nível de mestrado, no PPGE-UFSC, de Claudemir Osmar da Silva (SILVA, 2014) analisa, entre outros aspectos do REUNI, sua matriz de formação, as áreas que foram priorizadas e as propostas executadas.
} 


\section{Trabalhonecessário}

Issn: 1808 - 799X

ano 14 , número $23-2016$

Compreendemos que os industriais, quando defendem a democratização do ensino superior universitário, referem-se, na verdade, à ampliação da certificação nas áreas tecnológicas para seu exército industrial de reserva, por meio de um ensino baseado na pedagogia das competências (RAMOS, 2001), na Teoria do Capital Humano (SCHULTZ, 1967; 1973) e no ideário da sociedade do conhecimento (DE MARI, 2006). Em breves palavras: uma formação aligeirada e de muito baixa qualificação. Afinal, como dizem os industriais, no geral seus trabalhadores precisam de muito pouco para realizar o tipo de trabalho que executam. Isso denota, por outro lado, mesmo para profissionais com alguma qualificação - como no caso dos engenheiros -, que a subsunção real do trabalho ao capital exige muito pouca atividade criativa e intelectual. Na maior parte das vezes é mais necessário o registro profissional e a inserção de informações em softwares de projetos ${ }^{10}$, razão pela qual o par "avaliação" e "certificação" tornou-se central em detrimento - e, até mesmo, em oposição- da formação simbólica, sociológica, cognitiva, estética e assim por diante.

\section{A prestação de serviços, entre outros}

O segundo bloco de interesses dos empresários industriais, a produção de serviços, consultorias, desenvolvimento de produtos e a inovação tecnológica, foi gradualmente deslocado do eixo da Educação e ganhando espaço em separado nos documentos da Indústria. Ao menos para os industriais, tais políticas passaram a ter bases, fundamentos e destinos autonomizados e, portanto, passariam a ter formas de atividades estratégicas no Estado ampliado diferenciadas.

Ressalta-se que o Ministério da Ciência e Tecnologia (MCT), a Coordenação Nacional de Aperfeiçoamento de Pessoal de Nível Superior (CAPES), o Conselho Nacional de Desenvolvimento Científico e Tecnológico (CNPq), entre outros órgãos e

\footnotetext{
${ }^{10}$ Algumas faces da precarização do trabalho diante das novas tecnologias, numa espécie renovada de subsunção do homem como apêndice da máquina, recebeu um interessante tratamento no trabalho de Ricardo Antunes e Ruy Braga (ANTUNES; BRAGA, 2009).
} 


\section{Trabalhonecessário}

Issn: 1808 - 799X

ano 14 , número $23-2016$

entidades, públicas e privadas, estabeleceram programas de incentivo à inovação e à produção de serviços, além de outros específicos para desenvolvimento de produtos. Parece pertinente, pois, a hipótese de que os industriais paulatinamente deixaram de apresentar propostas para as universidades públicas e a reforma da educação superior, uma vez que encontraram junto ao Estado formas mais eficientes de disputas por seus interesse: Lei de Inovação Tecnológica (BRASIL, 2004a; 2016a), Lei das Parcerias Público-Privadas (BRASIL, 2004b), Plano Brasil Maior (BRASIL, 2016b), regulamentação das Fundações de Apoio (BRASIL, 2013), Lei do Bem (BRASIL, 2005), entre outros (GREGÓRIO, 2012; LEHER, 2004; MICHELOTTO, COELHO; ZAINKO, 2006; TRÓPIA, 2007; LIMA, 2011; SGUISSARDI, 2006; OTRANTO, 2006b).

Dessa forma, os dois aspectos dos interesses mencionados podem ser compreendidos, de acordo com Rodrigues (2007, p. 5), como:

[...] duas formas básicas de a burguesia, isto é, o capital, encarar a educação escolar: educação-mercadoria ou mercadoria-educação. Cada uma dessas perspectivas se liga diretamente à forma como o capital busca a autovalorização e cada uma delas é face de uma mesma moeda, ou seja, são formas sob as quais a mercadoria se materializa no campo da formação humana.

A forma da mercadoria-educação trata do modo como o capital encara a educação na forma de um insumo de tipo especial necessário à produção de outras mercadorias, neste caso, a força de trabalho. Para Rodrigues, este seria o caso mais comum dos empresários industriais, mas o autor ressalta que não basta que os trabalhadores sejam formados em número suficiente para formar o exército industrial de reserva; é necessário ainda que eles sejam formados com as qualidades requeridas pelo processo produtivo. Isso explica a criteriosa preocupação dos industriais com os aspectos formativos da educação universitária - com o conteúdo, com o encadeamento do fluxo do estudante desde o momento em que este se matricula, até o campo de estágios que realiza - e parecem dispostos a empenhar os 


\title{
Trabalhonecessário
}

Issn: 1808 - 799X

ano 14 , número $23-2016$

IEL em atividades cada vez mais íntimas entre aquilo que é ensinado e as demandas de suas empresas. Rodrigues (2007, p. 7) assinala que,

\begin{abstract}
Por um lado, a expansão rápida de profissionais graduados favorece imediatamente ao capital industrial, posto que cria um exército de reserva que tende a rebaixar os salários dessa categoria profissional. Por outro lado, se esse exército é constituído por graduados sem as devidas qualificações, isto é, qualidades requeridas pelo processo produtivo, a médio e longo prazo, o capital industrial poderá encontrar sérias dificuldades em seu processo produtivo.
\end{abstract}

Também é o caso quando o capital industrial demanda da universidade a prestação de serviços, consultorias, convênios com laboratórios e institutos de pesquisas, inovação tecnológica, entre outras formas espúrias de relação. Do ponto de vista destes interesses, a universidade é espaço de produção de conhecimentos que funcionam no processo de produção de suas mercadorias ordinárias, isto é, funciona como uma mercadoria-educação.

Os interesses mercantis e a prestação de Educação Superior

O terceiro conjunto de interesses dos industriais trata da forma como, por meio de suas entidades (IEL, SESI, SENAI, CNI), apresentam seus interesses mercantis na forma de prestadores de educação superior. Esse aspecto foi percebido por Martins, Tomaz \& Pina (2012, p. 189) na análise sobre a Federação das Indústrias de Minas Gerais (FIEMIG) e a Educação:

Verificamos que as relações entre Fiemig e CNI ultrapassam o campo da obediência legal e da formalidade. O télos da competitividade com responsabilidade social unificou e deu organicidade às ações, fortalecendo o projeto educativo da Fiemig. Considerando que a Fiemig consolidou o complexo SESI/SENAI como a maior rede de educação privada em Minas Gerais, é possível inferir que o projeto educativo da Federação tem um alcance considerável na formação humana no estado. (negrito nosso) 


\section{Trabalhonecessário}

Issn: 1808 - 799X

ano 14, número $23-2016$

De acordo com dados de 2009, divulgados pela CNI (2009), o SENAI possuía 721.317 estudantes matriculados em nível de formação inicial e continuada, 106.909 matriculados em educação profissional técnica de nível médio, 173.925 em educação de jovens e adultos para iniciação no trabalho e 12.441 no ensino superior. Não é possível ignorar o papel do Sistema Indústria na prestação de serviços educacionais, inclusive de educação profissional, tecnológica e superior, embora sejam necessárias mais pesquisas sobre essa dimensão. Esse quadro foi reconfigurado em 2014, com 2.201.355 de estudantes matriculados na formação inicial e continuada, 3.647.434 de matrículas na educação profissional, 27.053 na educação superior (SENAI, 2014). Estes dados demonstram que a tendência de crescimento da oferta de educação superior privada pelo sistema indústria (SESI, SENAI, IEL) segue aprofundando-se e evidenciam que os industriais consideram cada vez mais a educação como uma mercadoria a ser vendida. Esse aspecto será aprofundado adiante.

Em 2007 a CNI, SESI e SENAI divulgaram o documento Educação para a nova indústria, no qual além de reiterarem as bases político-pedagógicas da Teoria do Capital Humano e sua concepção de educação voltada para a sociedade do conhecimento, estabeleceram uma série de propostas que reorientavam o SENAI como espaço central e organizador da formação inicial, continuada e profissionalizante dos trabalhadores da indústria. Afinada com as concepções políticas e morais estabelecidas nos discursos dos industriais, essa formação muito se assemelha com a análise sobre a FIEMIG:

O esforço da FIEMIG ao longo dos anos 2000 foi primordialmente atualizar o projeto educativo empresarial no contexto de crescimento da economia nacional para oferecer à sociedade em geral e aos trabalhadores da indústria e seus familiares, de forma específica, referências morais, intelectuais e comportamentais compatíveis com a dinâmica social e econômica da chamada "sociedade do conhecimento" (MARTINS; TOMAZ; PINA, 2012, p. 189). 


\section{Trabalhonecessário}

Issn: 1808 - 799X

ano 14, número $23-2016$

Fica clara a estratégia do Sistema Indústria de se posicionar como prestador de serviços educacionais privados, organizados pelo SENAI. De novo a posição de Rodrigues (2007, p. 6) é pertinente quando considera que

[...] se um capital em particular estiver buscando sua valorização a partir da venda de serviços educacionais, tais como o capital investido em instituições de ensino, sejam elas escolas ou universidades, esse capital comercial tenderá a tratar a prática social educacional como uma mercadoria cujo fim é ser vendida no mercado educacional. Em outras palavras, o serviço educacional, como um curso de graduação prestado por uma universidade (em geral, privada), é caso tipíco da educação-mercadoria. (negrito nosso).

Ao desempenhar o papel de vendedor de serviços educacionais a Indústria toma a educação por educação-mercadoria, seja pela cobrança de mensalidades, seja pelo brutal montante de dinheiro público repassado às suas escolas privadas por meio de programas governamentais. Os mecanismos políticos de captura de dinheiro público precisariam ser analisados com maior profundidade ${ }^{11}$, mas um importante instrumento é o Programa Nacional de Acesso ao Ensino Técnico e Emprego - PRONATEC ${ }^{12}$ (BRASIL, 2011).

\section{A dupla dimensão da relação Mercadoria-Educação/Educação-Mercadoria}

A dupla dimensão dos interesses dos industriais - mercadoria-educação, educação-mercadoria - parece repercutir significativamente em suas propostas, como

\footnotetext{
11 O limite deste artigo impôs a indicação de apenas alguns elementos que surgiram na análise da empiria; contudo, mostram um interessante aspecto sobre o papel dos empresários industriais como proprietários de instituições privadas de educação superior.

${ }_{12}$ Assim como outros programas do Governo Federal sob a gestão do Partido dos Trabalhadores, tal como o Programa Universidade para Todos (PROUNI) (BRASIL, 2005), o PRONATEC concede bolsas aos estudantes de cursos técnicos e profissionalizantes. Ofertantes significativos têm sido as instituições do Sistema S: Serviço Nacional de Aprendizagem Comercial (SENAC), Serviço Nacional de Aprendizagem Industrial (SENAI) e o Serviço Social da Indústria (SESI).
} 


\section{Trabalhonecessário}

Issn: 1808 - 799X

ano 14, número $23-2016$

vimos. Enquanto toma a educação como mercadoria-educação, os industriais preocupam-se em formar aligeiradamente seus trabalhadores por meio da formatação de competências profissionais básicas, das concepções pedagógicas lastreadas na Teoria do Capital Humano e da sociedade do conhecimento. Tais bases, procuramos demonstrar, formam articulações ideológicas; condensam ao mesmo tempo um conjunto de identificações para a classe trabalhadora no sentido de desapropriá-la como classe e organizá-la como indivíduos ${ }^{13}$ (como fins e meios de seus próprios investimentos e retornos financeiros na venda da força de trabalho) e, por outra via, encobrem as condições reais de trabalho, emprego e renda.

Os industriais almejam destruir quaisquer resistências institucionais aos seus interesses, articulando referências exteriores à realidade brasileira - são tomados como modelos de reformas universitárias a americana, chinesa, coreana e o Processo de Bolonha - para propor seus slogans educacionais. Do ponto de vista de Seki (2014, p. 141),

O capital procura apresentar a lógica gerencial-mercantil como modelo universal de "gestão de negócios", pois para ele pouco importa se a mercadoria que compra é minério de ferro ou força de trabalho; interessa-se apenas em colocá-la ao menor custo e em menor tempo no processo produtivo e na circulação. É inegável que os empresários da indústria não têm qualquer interesse na educação integral dos trabalhadores. Para eles, a educação ocupa-se demais com conteúdos que não interessam aos processos produtivos. Seus reais interesses, perceptíveis na análise acurada de seus documentos, concentram-se na certificação, em larga escala, de engenheiros e tecnólogos.

Quando os industriais tomam a educação como educação-mercadoria deixam perceber que podem dominar a produção dos insumos da mercadoria especial de que necessitam no chão-de-fábrica. Esse domínio diz respeito à venda de serviços

\footnotetext{
$13 \mathrm{Um}$ forte aspecto dessa documentação refere-se ao empreendedorismo que aparece de forma marginal na documentação dos industriais, porém parece guardar estreito vínculo com seu ideário. Possivelmente ele seja tratado em documentos não específicos para a educação superior. Uma discussão importante sobre a educação para o empreendedorismo pode ser encontrada na Tese de Doutorado de Marival Coan, Educação para o empreendedorismo: implicações epistemológicas, políticas e práticas, defendida no PPGE-UFSC (COAN, 2011).
} 


\section{Trabalhonecessário}

Issn: 1808 - 799X

ano 14 , número $23-2016$

educacionais diretos ao trabalhador ou ao que é mais lucrativo: a venda de matrículas ao Estado, com enormes transferências de dinheiro público às IES privadas. Dessa forma, os industriais encontram as condições de realizar a formação de seus trabalhadores ao seu modo, nas áreas profissionais que demandam maior ou menor contingente de trabalhadores. Disporiam, também, de meios de formação das consciências dos trabalhadores que estudam em suas instituições e ainda poderiam lançar mão de novos slogans no campo da "responsabilidade social":

Se a década de 1990 foi um período da reestruturação produtiva com efeitos importantes sobre a condição de vida do trabalhador (FRIGOTTO, 1995; ANTUNES, 1999; ALVES, 2005), a década de 2000 pode ser identificada como consolidação desse processo e aprofundamento de referências políticas, ampliando o télos empresarial da "competitividade" (RODRIGUES, 1998) para um novo télos: a "competitividade com responsabilidade social" (MARTINS, 2009). Isso significa relacionar num mesmo projeto de desenvolvimento o econômico com o social. (MARTINS; TOMAZ; PINA, 2012, p. 187)

Ao tomar a educação superior como educação-mercadoria, os industriais encontraram um modo de fazer educação nos moldes de seus interesses mercantis. Nos limites de sua conveniência, livram-se circunstancialmente da necessidade de reformar uma instituição que, em sua visão, é difícil de transformar pelo forte caráter de resistência de partidos, sindicatos e movimentos sociais: a universidade pública. Isso nos permite compreender, parcialmente, seu investimento na gradual extinção dessas instituições com consequente repasse de recursos para a educação básica e profissionalizante privadas (CNI, 2010).

\section{Da educação-mercadoria à mercadoria-educação}




\section{Trabalhonecessário}

Issn: 1808 - 799X

ano 14 , número $23-2016$

Há ainda dois outros aspectos que gostaríamos de tratar em razão de seu potencial para pesquisas que podem se somar no futuro às contribuições críticas encontradas na literatura acadêmica ${ }^{14}$. Ambos dizem respeito ao deslocamento produzido na documentação da Indústria e que sintetizamos na formulação: da educação-mercadoria à mercadoria-educação.

O primeiro ponto refere-se ao fato de que, durante o Governo Lula, aprofundavam-se as relações internas à dinâmica de compra e venda de capitais por meio de fundos de investimentos, ou seja, na dinâmica de acumulação do capitalismo dependente brasileiro (FERNANDES, 1981, 2005, 2008; MARINI, 2011, 2012; BAMBIRRA, 2012; FONTES, 2010). Verticalizavam-se, assim, os vínculos de valorização financeira do capital (CHESNAIS, 2005; FONTES, 2010), entre outros meios, pelos fundos de investimento. Essa ideia nos auxilia a compreender a existência de fundos - nisto pode-se incluir os fundos de pensão, com fortes contradições para a organização da classe trabalhadora (SAUVIAT, 2005, p. 109-132) - que detêm a propriedade de capitais de frações ou ramos distintos nas atividades econômicas. Assim, um mesmo fundo de investimento pode ser proprietário de capitais financeiros, bancários, industriais, agronegócios etc. Essa dinâmica altera o comportamento particular de frações do capital, complexificando o trabalho analítico sobre a associatividade inter-burguesa (FONTES, 2010, p. 215-222; BIANCHI, 2010), chegando ao ponto em que é difícil distinguir seus interesses particulares. Parece-nos que a financeirização do capital possibilita certa diluição das características singulares e estabelecem novos desafios analíticos devido ao alto grau de complexidade dos obstáculos enfrentados na compreensão das demandas burguesas no âmbito do Estado ampliado. A articulação entre propostas políticas para a educação superior do Banco Mundial e CNI/SESI/SENAI/IEL e a dupla tomada de papeis pelos empresários industriais (educação-mercadoria e mercadoria-educação) talvez sejam expressões

\footnotetext{
14 Leher (2004); Micheloto, Coelho \& Zainko (2006); Otranto, (2006); Sguissardi (2006); Rodrigues (2007b); Trópia (2007, 2009); Abreu (2010); Lima (2011); Gregório (2012); De Paula (2008), entre outros.
} 


\section{Trabalhonecessário}

Issn: 1808 - 799X

ano 14, número $23-2016$

desses processos de ampliação das fronteiras de financeirização das relações sob o capital $^{15}$.

A diversificação da cesta de investimentos dos industriais atingiu também a compra e venda de serviços educacionais. Além de encarar a educação como um insumo para a formação, qualificação ou certificação da força de trabalho, agora a encaram também como mercadoria a ser produzida e vendida nas relações mercantis. Além de terem maior controle sobre o tipo de ideologia que dirige essa educação, podem também fazer dessa mercadoria um meio de acumulação de capital. Sobre esse aspecto, é relevante investigações futuras que analisem o montante de recursos do orçamento público da educação repassados à indústria por meio de programas educacionais nos municípios, estados e da União. A isso denominamos: da educaçãomercadoria à mercadoria-educação. Nossa hipótese é justamente a de que a complexificação da posse da propriedade, ocasionada pelo fortalecimento dos fundos propriamente financeiros, é o passo decisivo desse deslocamento.

Um outro aspecto é flagrante: o elevado nível de associatividade inter-buguesa (FONTES, 2010) ou Ação Coletiva Empresarial (BIANCHI, 2010) da burguesia interna brasileira e a criação de diferentes fronts de empresários. O Movimento Todos pela Educação (EVANGELISTA; LEHER, 2012; MARTINS, 2009) ${ }^{16}$ ilustra a associação entre empresários de diferentes ramos da atividade econômica ${ }^{17}$ e sua capacidade de produzir um corpo de propostas educacionais em consenso. Fontes (2010, p. 309310) é precisa:

\footnotetext{
${ }^{15} \mathrm{~A}$ compra e venda de títulos de propriedade de capitais em mercados de valores talvez tenda, além da diluição de certas características particulares das frações burguesas internas, a diminuir o grau de tensão entre aquilo que chamamos de burguesia interna e externa. Talvez aí resida certa dificuldade teórica no momento de caracterizarmos a relação entre empresários da burguesia interna e externa como, no caso, a relação entre Banco Mundial e a Confederação Nacional da Indústria; nenhuma palavra parece expressar precisamente essa relação.

16 Os autores analisam as expressões políticas do Movimento Todos pela Educação, em diferentes níveis e instâncias, como generalização da ação dos empresários estreitamente imbricados no Estado. 17 O movimento Todos pela Educação tem como sócios fundadores empresas e fundações como: DPaschoal, Gerdau, Instituto Camargo Corrêa, Suzano Papel e Celulose, Telefônica, Instituto Península, Vale do Rio Doce, Fundação Itaú Social, Fundação Bradesco, Itaú BBA, Fundação Lemann. (EVANGELISTA; LEHER, 2012; MARTINS, 2009).
} 


\section{Trabalhonecessário}

Issn: 1808 - 799X

ano 14, número $23-2016$

[...] se complexificou o teor da sociabilidade dominante no Brasil contemporâneo, tanto no que concerne às lutas populares e suas transformações, quanto com relação às múltiplas formas de ação burguesa no Brasil atual. A abordagem adotada enfatizou as formas de organização da dominação burguesa e discrepa de muitas análises que ora enfatizam a inorganicidade burguesa no Brasil, insistindo sobre sua ligação direta com o Estado (sublinhando, por exemplo, as noções de patrimonialismo ou clientelismo), ora acentuam unilateralmente o aspecto truculento da dominação no Brasil, o que, embora real, não é suficiente para dar conta dos processos atuais. Como demonstraram as pesquisas de Sônia Regina de Mendonça, [...] a teia de organizações burguesas no Brasil atravessou todo o século $X X$, assim como seu entrelaçamento no Estado, cuja ampliação foi extremamente seletiva.

A burguesia industrial brasileira não é uma burguesia frágil, vítima de pressões internacionais, obrigada a aderir aos ditames do capital internacional e das frações internas. Lastreada em Florestan Fernandes, Fontes (2010, p. 311) afirma:

Como fartamente demonstrou Florestan Fernandes, a burguesia aqui forjada estava articulada socialmente em bases nacionais, sendo pois sua fraqueza apenas relativa, premida pelas injunções de uma dupla articulação promotora de permanente tensão entre o desenvolvimento desigual no interior do país e o que ele designa como imperialismo total.

Para a autora, a burguesia industrial brasileira também não ocupa a posição de uma burguesia nacional:

A existência da burguesia como classe "nacional", atuante e impondo sua ordem, de maneira unificada (embora contraditória) em todo o território, não a converteria na famosa "burguesia nacional", da qual se esperava um processo revolucionário de cunho democratizante e fortemente anti-imperialista, disposta a enfrentar a grande propriedade rural e a dirigir um processo de incorporação republicana dos setores subalternos. [...] O argumento de Florestan consolida nossa hipótese de uma burguesia brasileira, integrada de maneira heterogênea, sobretudo por nativos, mas também por fortíssimos interesses originados em outros países, em especial nos Estados Unidos, aqui implantados. (FONTES, 2010, p. 311-312) 


\section{Trabalhonecessário}

Issn: 1808 - 799X

ano 14, número $23-2016$

A concepção de Fontes (2010) pareceu relevante para destacar que a relação dos empresários industriais com Organizações Multilaterais, a exemplo do Banco Mundial, assim como a articulação de um projeto pedagógico que toma por base concepções como capital humano ou sociedade do conhecimento, longe de demonstrar a submissão desse empresariado aos projetos das burguesias internacionais, evidencia o alto grau de articulação entre esses sujeitos históricos e o caráter antinacional da burguesia brasileira e, nela, do empresariado industrial. Cabe aqui a advertência de Marini (2012, p. 27-28):

A evolução da ciência social latino-americana nos anos recentes apesar da frequente reincidência em antigos equívocos - contribuiu com elementos suficientes para invalidar uma das teses que me esforcei aqui em combater: aquela de que o regime militar brasileiro era um simples efeito da ação desse deus ex-machina representado para alguns pelo imperialismo estadunidense. Não é em prol do imperialismo que se deve criticar esse tipo de análise, mas em função das possibilidades das massas exploradas da América Latina abrirem caminho à própria libertação. As consequências do conhecido símbolo gráfico que coloca o malvado Tio Sam manipulando suas marionetes não podem ser mais que denúncia lacrimosa e impotência indignada para a análise política e a estratégia de luta. Para lutar contra o imperialismo é indispensável entender que não se trata de um fator externo à sociedade nacional latino-americana, mas, pelo contrário, forma o terreno no qual esta sociedade finca suas raízes e constitui um elemento que a permeia em todos seus aspectos.

Existia para Fernandes (2010) uma dupla expectativa histórica: a primeira, a de que uma revolução dentro da ordem pudesse fermentar a constituição de uma burguesia nacional capaz de criar condições para o desenvolvimento de um capitalismo autônomo e republicanizar as formas sociais no Brasil; a segunda seria a de uma revolução contra a ordem, levada a cabo por aquela "gentinha sem eira nem beira" (FONTES, 2010, p. 313). Florestan conclui que sequer a primeira expectativa se realizou: 


\section{Trabalhonecessário}

Issn: 1808 - 799X

ano 14 , número $23-2016$

De pronto, observa-se que tal revolução democrática não é burguesa. [...] é uma revolução que eclode dentro da ordem, mas que se aninha na parte excluída e ignorada dessa mesma ordem. [...] Os de cima tentam domesticá-la, canalizá-la institucionalmente, enquadrá-la em uma República burguesa de democracia relativa ou de segurança nacional. (FERNANDES, 1986, p. 58 apud FONTES, 2010, p. 313).

\section{Considerações finais}

Na presente pesquisa analisamos as propostas educacionais da Confederação Nacional da Indústria (CNI) - fração específica do capital - para as universidades públicas no Governo de Luís Inácio Lula da Silva (2003-2010). Estudamos o projeto dos empresários industriais, especificamente a $\mathrm{CNI}$ e suas entidades complementares: SESI, SENAI e IEL.

O exame dos documentos que abrangem os dois mandatos presidenciais de Lula possibilitou perceber que a CNI modificou suas proposições para as universidades públicas ao longo do tempo. No início do Governo Lula os industriais propunham formas de privatização que não aquelas compreendidas no sentido estrito; defendiam, assim, algum aspecto ainda de gratuidade do ensino de graduação para os estudantes, porém vinculando-o à flexibilização de cursos, à desconstrução do sentido público das universidades em sua dimensão ensino-pesquisa-extensão, à incorporação do empreendedorismo na matriz pedagógica, bem como à introdução do gerencialismo e outras ideologias próprias do empresariado. Ao final do Governo Lula, os industriais entendiam que a prioridade devia ser dada à Educação Básica, que as universidades públicas deveriam ser extintas e seus recursos repassados aos demais níveis de ensino, fomentando-se a privatização em sentido estrito, isto é, o empresariamento do Ensino Superior.

Ao longo do trabalho, procuramos apresentar argumentos que demonstram um projeto educacional altamente destrutivo dos aspectos formativos da educação pública nas universidades. Procuramos também levantar a questão de que tal 


\section{Trabalhonecessário}

Issn: 1808 - 799X

ano 14 , número $23-2016$

realidade exigirá ainda mais refinamentos de nossas análises, na medida em que apresenta uma acumulação de capitais cada vez mais dinâmica e complexa, impulsionada pela sua financeirização.

Constatamos que o capital industrial constituiu um ideário pedagógico, no final do segundo Governo Lula, cujas bases estão na "Teoria do Capital Humano" e na concepção de "sociedade do conhecimento". Do ponto de vista da classe trabalhadora, não existe qualquer elemento positivo no ideário de tais empresários. Para a construção de projetos políticos que resgatem o papel da universidade brasileira e seu sentido público, a classe trabalhadora deve romper absolutamente com qualquer projeto de aliança com os industriais.

Sobre esse último aspecto, é possível que alguns imaginassem que a fração industrial interna pudesse vir a tornar-se aliada da classe trabalhadora na construção de um projeto de reforma universitária autônomo, barreira de combate das expressões da dependência tecnológica e parte do momento de lutas anti-imperialistas tão necessárias ao nosso povo. Ledo engano, posto que as evidências não deixam margem para equívocos: definitivamente não é o caso! Dos fundamentos de seu projeto às suas propostas - que passam tanto pelo empresariamento da educação, quanto pela privatização em sentido estrito -, os industriais não apresentam qualquer traço positivo para um projeto educacional com a potência de se tornar contra hegemônico. Para a classe trabalhadora inexiste qualquer possibilidade de aliança com esta fração do empresariado brasileiro.

A educação do homem omnilateral (GRASMCl, 1979) e a defesa da escola unitária (GRASMCI, 1979) só pode estar referida à segunda expectativa histórica descrita por Florestan Fernandes: uma reforma universitária que aconteça como parte de um processo revolucionário e que deverá ser realizada, ainda que dentro dessa mesma ordem, fortemente vinculada aos interesses das maiorias que compõem a classe trabalhadora. À classe trabalhadora, e seus aliados, cabe colocar em cena seus próprios projetos e por seus próprios meios. 


\section{Trabalhonecessário}

Issn: 1808 - 799X

ano 14, número $23-2016$

\section{REFERÊNCIAS}

ABREU, Maria Aparecida Azevedo. Educação: um novo patamar institucional. Novos Estudos - CEBRAP, n. 87, p. 131-143, 2010.

ANTUNES, R.; BRAGA, R. (orgs.) Infoproletários: degradação real do trabalho virtual. São Paulo: Boitempo, 2009. 252 p.

BAMBIRRA, Vânia. O capitalismo dependente latino-americano. Florianópolis: Insular, 2012. 224 p. Tradução de Fernando Correa Prado \& Marina Machado Gouvêa.

BIANCHI, Álvaro Gabriel. Um ministério dos industriais: a Federação das Indústrias do Estado de São Paulo na crise das décadas de 1980 e 1990. Campinas: Editora da Unicamp, 2010. 287 p.

BRASIL. Lei $n^{\circ} 10.973$, de 2 de dezembro de 2004. Dispõe sobre incentivos à inovação e à pesquisa científica e tecnológica no ambiente produtivo e dá outras providências. 2004a. Disponível em: <http://www.planalto.gov.br/ccivil 03/ ato20042006/2004/lei/l10.973.htm >. Acesso em: 10 mar. 2016.

BRASIL. Lei $n^{\circ} 11.079$, de 30 de dezembro de 2004. Institui normas gerais para licitação e contratação de parceria público-privada no âmbito da administração pública. 2004b. Disponível em: <http://www.planalto.gov.br/ccivil 03/ ato20042006/2004/lei/l11079.htm>. Acesso em: 10 mar. 2016.

BRASIL. Lei $\mathrm{n}^{\circ} 11.096$, de 13 de janeiro de 2005. Institui o Programa Universidade para Todos -PROUNI, regula a atuação de entidades beneficentes de assistência social no ensino superior; altera a Lei no 10.891 , de 9 de julho de 2004, e dá outras providências. Disponível em: <http://www.planalto.gov.br/ccivil 03/ ato20042006/2005/lei/L11096.htm >. Acesso em: 10 mar. 2016.

BRASIL. Lei no 11.196, de 21 de novembro de 2005. Institui o Regime Especial de Tributação para a Plataforma de Exportação de Serviços de Tecnologia da Informação - REPES, o Regime Especial de Aquisição de Bens de Capital para Empresas Exportadoras - RECAP e o Programa de Inclusão Digital; dispõe sobre incentivos fiscais para a inovação tecnológica; altera o Decreto-Lei no 288, de 28 de fevereiro de 1967, o Decreto no 70.235, de 6 de março de 1972, o Decreto-Lei no 2.287, de 23 de julho de 1986, as Leis nos 4.502, de 30 de novembro de 1964, 8.212, de 24 de julho de 1991, 8.245, de 18 de outubro de 1991, 8.387, de 30 de dezembro de 1991, 8.666, de 21 de junho de 1993, 8.981, de 20 de janeiro de 1995, 8.987, de 13 de fevereiro de 1995, 8.989, de 24 de fevereiro de 1995, 9.249, de 26 de dezembro de 1995, 9.250, de 26 de dezembro de 1995, 9.311, de 24 de outubro de 1996, 9.317, de 5 de 


\section{Trabalhonecessário}

Issn: 1808 - 799X

ano 14 , número $23-2016$

dezembro de 1996, 9.430, de 27 de dezembro de 1996, 9.718, de 27 de novembro de 1998, 10.336, de 19 de dezembro de 2001, 10.438, de 26 de abril de 2002, 10.485, de 3 de julho de 2002, 10.637, de 30 de dezembro de 2002, 10.755, de 3 de novembro de 2003, 10.833, de 29 de dezembro de 2003, 10.865, de 30 de abril de 2004, 10.925, de 23 de julho de 2004, 10.931, de 2 de agosto de 2004, 11.033, de 21 de dezembro de 2004, 11.051, de 29 de dezembro de 2004, 11.053, de 29 de dezembro de 2004, 11.101, de 9 de fevereiro de 2005, 11.128, de 28 de junho de 2005, e a Medida Provisória no 2.199-14, de 24 de agosto de 2001; revoga a Lei no 8.661, de 2 de junho de 1993, e dispositivos das Leis nos 8.668 , de 25 de junho de 1993, 8.981, de 20 de janeiro de 1995, 10.637, de 30 de dezembro de 2002, 10.755, de 3 de novembro de $2003,10.865$, de 30 de abril de 2004, 10.931, de 2 de agosto de 2004, e da Medida Provisória ํo2.158-35, de 24 de agosto de 2001; e dá outras providências. 2005. Disponível em: <http://www.planalto.gov.br/ccivil 03/ ato20042006/2005/lei//11196.htm>. Acesso em: 10 mar. 2016.

BRASIL. Lei no 12.863, de 24 de setembro de 2013. Altera a Lei no 12.772, de 28 de dezembro de 2012, que dispõe sobre a estruturação do Plano de Carreiras e Cargos de Magistério Federal; altera as Leis nos 11.526, de 4 de outubro de 2007, 8.958, de 20 de dezembro de 1994, 11.892, de 29 de dezembro de 2008, 12.513, de 26 de outubro de 2011, 9.532, de 10 de dezembro de 1997, 91, de 28 de agosto de 1935, e 12.101, de 27 de novembro de 2009; revoga dispositivo da Lei no 12.550, de 15 de dezembro de 2011; e dá outras providências. 2013. Disponível em: <http://www.planalto.gov.br/ccivil 03/ ato2011-2014/2013/Lei/L12863.htm>. Acesso em: 10 mar. 2016.

BRASIL. SAPI. Plano Brasil Maior. Inovar para competir.2016b. Disponível em: $<$ http://www.brasilmaior.mdic.gov.br/conteudo/125>. Acesso em: 10 mar. 2016.

BRASIL. Lei o 12.513, de 26 de outubro de 2011. Institui o Programa Nacional de Acesso ao Ensino Técnico e Emprego (Pronatec); altera as Leis no 7.998, de 11 de janeiro de 1990, que regula o Programa do Seguro-Desemprego, o Abono Salarial e institui o Fundo de Amparo ao Trabalhador (FAT), no 8.212, de 24 de julho de 1991, que dispõe sobre a organização da Seguridade Social e institui Plano de Custeio, no 10.260, de 12 de julho de 2001, que dispõe sobre o Fundo de Financiamento ao Estudante do Ensino Superior, e no 11.129, de 30 de junho de 2005, que institui o Programa Nacional de Inclusão de Jovens (ProJovem); e dá outras providências. 2011. Disponível em: <http://www.planalto.gov.br/ccivil 03/ ato20112014/2011/lei//12513.htm>. Acesso em: 10 mar. 2016.

BRASIL. Lei $\mathrm{n}^{0} 13.243$, de 11 de janeiro de 2016. Dispõe sobre estímulos ao desenvolvimento científico, à pesquisa, à capacitação científica e tecnológica e à inovação e altera a Lei o 10.973, de 2 de dezembro de 2004, a Lei no 6.815, de 19 de agosto de 1980, a Lei n-8.666, de 21 de junho de 1993, a Lei no 12.462, de 4 de agosto 


\section{Trabalhonecessário}

Issn: 1808 - 799X

ano 14 , número $23-2016$

de 2011, a Lei oㅡ 8.745, de 9 de dezembro de 1993, a Lei o 8.958, de 20 de dezembro de 1994, a Lei no 8.010, de 29 de março de 1990, a Lei o 8.032, de 12 de abril de 1990, e a Lei no 12.772, de 28 de dezembro de 2012, nos termos da Emenda Constitucional o 85, de 26 de fevereiro de 2015. 2016a.Disponível em: $<$ http://www.planalto.gov.br/ccivil 03/ Ato2015-2018/2016/Lei/L13243.htm>. Acesso em: 10 mar. 2016.

CHESNAIS, François (org.). A finança mundializada: raízes sociais e políticas, configuração, consequências. São Paulo: Boitempo, 2005. 255 p.

COAN, Marival. Educação para o empreendedorismo: implicações epistemológicas, políticas e práticas. 2011. Tese (Doutorado em Educação) - UFSC, Florianópolis. Disponível em: $<$ https://repositorio.ufsc.br/bitstream/handle/123456789/94847/298002.pdf?sequence =1>. Acesso em: 10 mar. 2016.

CONFEDERAÇÃO NACIONAL DA INDÚSTRIA - CNI (Brasil). Indicadores SENAI. $2009 . \quad$ Disponível em: <http://www.sesi.org.br/infografico/indicadores/anteriores/antigos/Indicadores SENAI 2008_atuali_19_02_2010.swf >. Acesso em: 30 jul. 2014.

CONFEDERAÇÃO NACIONAL DA INDÚSTRIA - CNI (Brasil). Contribuição da indústria para a reforma da educação superior. Brasília: CNI/SESI/SENAI/IEL, 2004

CONFEDERAÇÃO NACIONAL DA INDÚSTRIA - CNI (Brasil). Contribuição da indústria para a reforma da educação superior: análise da segunda versão do anteprojeto. Brasília: CNI/SESI/SENAI/IEL, 2005

CONFEDERAÇÃO NACIONAL DA INDÚSTRIA - CNI (Brasil). Educação para a nova indústria. Brasília: CNI, 2007.

CONFEDERAÇÃO NACIONAL DA INDÚSTRIA - CNI (Brasil). A indústria e o Brasil, uma agenda para crescer mais e melhor. Brasília: CNI, 2010.

CONFEDERAÇÃO NACIONAL DA INDÚSTRIA - CNI (Brasil). Educação para a nova indústria. Brasília: CNI, 2007.

DE PAULA, Cristiana Maria. Neoliberalismo e reestruturação da educação superior no Brasil: o REUNI como estratégia do governo Lula e da burguesia brasileira para subordinar a universidade federal à lógica do atual estágio de acumulação do capital. 246 f. Dissertação (Mestrado) - Universidade Federal Fluminense, Niterói, 2009.

DE MARI, Cezar L. "Sociedade do Conhecimento" e Educação Superior na década de 1990: O Banco Mundial e a produção do desejo irrealizável de Midas. 2006. Tese 


\section{Trabalhonecessário}

Issn: 1808 - 799X

ano 14 , número $23-2016$

(Doutorado em Educação) - UFSC, Florianópolis. Disponível em: $<$ https://repositorio.ufsc.br/bitstream/handle/123456789/88827/225653.pdf?sequence $\equiv 1>$. Acesso em: 10 mar. 2016.

EVANGELISTA, Olinda; LEHER, Roberto. Todos pela educação e o episódio Costin no MEC: a pedagogia do capital em ação na política educacional brasileira. Trabalho Necessário, Niterói, v. 10, n. 15, p.1-29, jul. 2012. Disponível em: <http://www.uff.br/trabalhonecessario/images/TN1519 Artigo Roberto Leher e Olinda Evangelista.pdf>. Acesso em: 02 ago. 2014.

FERNANDES, Florestan. Capitalismo dependente e classes sociais na América Latina. 3. ed. Rio de Janeiro: Zahar, 1981. 157 p.

FERNANDES, Florestan. A revolução burguesa no Brasil: ensaios de interpretação sociológica. 5. ed. São Paulo: Globo, 2005. 504 p.

FERNANDES, Florestan. Sociedade de classes e subdesenvolvimento. 5. ed. rev. São Paulo: Globral, 2008. 253 p.

FONTES, Virgínia. O Brasil e o capital-imperialismo: teoria e história. 2. ed. Rio de Janeiro: EPSJV/Editora UFRJ, 2010. 388 p.

FORMIGA, Manuel Marcos Maciel; CARMO, Luiz Carlos Scavarda do (Org.). Engenharia para o desenvolvimento: Inovação, sustentabilidade, responsabilidade social como novos paradigmas. Brasília: SENAI/DN, 2010. 212 p.

GRAMSCI, Antonio. Maquiavel, a política e o Estado moderno. Rio de Janeiro: Civilização Brasileira, 1978.

GRAMSCI, Antonio. Os intelectuais e a organização da cultura. Rio de Janeiro: Civilização Brasileira, 1979.

GREGÓRIO, José Renato Bez de. Contrarreforma da educação superior no governo Lula da Silva. Revista Ver a Educação, v. 12, n. 1, p. 29-64, 2012.

LÉDA, Denise Bessa; MANCEBO, Deise. REUNI: heteronômia e precarização da universidade e do trabalho docente. Educação \& Realidade, v. 34, n. 1, p. 49-64, 2009.

LEHER, Roberto. Para silenciar os campi. Educação \& Sociedade, v. 25, n. 88, p. 867891, 2004.

LIMA, Kátia Regina de Souza. O Banco Mundial e a educação superior brasileira na primeira década do novo século. Revista Katálysis, v. 14, n. 1, p. 86-94, 2011.

MANDELI, Aline de S. Fábrica de professores em nível superior: a Universidade Aberta do Brasil (2003-2014). 2014. Dissertação (Mestrado em Educação)- 


\section{Trabalhonecessário}

Issn: 1808 - 799X

ano 14 , número $23-2016$

Universidade Federal de Santa Catarina, Florianópolis, SC, 2014. (Nota: defendida em Agosto de 2014).

MARINI, Ruy Mauro. Dialética da dependência. In: TRASPADINI, Roberta; STEDILE, João Pedro (orgs.). Ruy Mauro Marini: vida e obra. 2. ed. São Paulo: Expressão Popular, 2011.292 p.

MARINI, Ruy Mauro. Subdesenvolvimento e revolução. 3. ed. Florianópolis: Insular, 2012. 272 p. Tradução de Fernando Correa Prado \& Marina Machado Gouvêa.

MARTINS, André. A educação básica no século XXI: o projeto do organismo "Todos pela Educação". Práxis Educativa, v. 4, n. 1, 2009. Disponível em: http://dx.doi.org/10.5212/PraxEduc.v.4i1.021028. Acesso em: 10 mar. 2016.

MARTINS, André Silva; TOMAZ, Adriane Silva; PINA, Leonardo Docena. Empresários e educação: reflexões sobre o projeto educacional da federação das indústrias de minas gerais. Educação em Foco, Juiz de Fora, v. 18, n. 1, p.179-207, jun. 2012.

MICHELOTTO, Regina Maria; COELHO, Rúbia Helena; ZAINKO, Maria Amélia Sabbag. A política de expansão da educação superior e a proposta de reforma universitária do governo Lula. Educar, Curitiba, n. 28, p. 179-198, 2006.

OTRANTO, Celia Regina. Desvendando a política da educação superior do governo Lula. Universidade e Sociedade, v. 16, n. 38, p. 19-29, 2006.

PORTUGAL. UC. Grupo de Missão para o Espaço Europeu de Ensino Superior. $O$ Processo de Bolonha. $2016 . \quad$ Disponível em: <http://www.uc.pt/ge3s/pasta guia ge3s/proc bolonha/>. Acesso em: 10 mar. 2016.

RAMOS, Marise N. Pedagogia das competências: autonomia ou adaptação? São Paulo: Cortez, 2001.

RODRIGUES, José. Os empresários e a educação superior. Campinas: Autores Associados, 2007b. 95 p.

RODRIGUES, José. Frações burguesas em disputa e a educação superior no Governo Lula. Revista Brasileira de Educação, Rio de Janeiro, v. 12, n. 34, p.120-136, abr. 2007a.

SAUVIAT, Catherine. Os fundos de pensão e os fundos mútuos: principais atores da finança mundializada e do novo poder acionário. In: CHESNAIS, François (Org.). A finança mundializada. São Paulo: Boitempo, 2005

SCHULTZ, Theodore W. O valor econômico da educação. Rio de Janeiro: Zahar, 1967. 


\section{Trabalhonecessário}

Issn: 1808 - 799X

ano 14, número $23-2016$

SERVIÇO NACIONAL DE APRENDIZAGEM INDUSTRIAL - SENAI; INSTITUTO EUVALDO LODI - IEL (Brasil). Inova Engenharia: Proposta para a modernização da educação em engenharia no Brasil. Brasília: SENAI/IEL, 2006. 105 p.

SCHULTZ, Theodore. O Capital Humano: investimentos em educação e pesquisa. Rio de Janeiro: Zahar, 1973.

SEKI, Allan Kenji. O capital e as universidades federais no governo Lula: o que querem os industriais? 2014. 169 p. Dissertação (Mestrado) - Universidade Federal de Santa Catarina, Centro de Ciências da Educação, Programa de Pós-Graduação em Educação, Florianópolis, 2014.

SERVIÇO NACIONAL DE APRENDIZAGEM INDUSTRIAL - SENAI (Brasil). Confederação Nacional da Indústria. Relatório Anual 2014. 2014. Disponível em: $<$ http://arquivos.portaldaindustria.com.br/app/conteudo 18/2015/05/20/356/RelatrioA nualdoSESISENAleIEL-2014.pdf>. Acesso em: 20 mar. 2016.

SILVA, Claudemir Osmar da. Programa Reuni: ampliação do acesso ao ensino superior?2014. 163 p. Dissertação (Mestrado) - Universidade Federal de Santa Catarina, Centro de Ciências da Educação, Programa de Pós-Graduação em Educação, Florianópolis, 2014.

SGUISSARDI, Valdemar. Reforma universitária no Brasil-1995-2006: precária trajetória e incerto futuro. Educação \& Sociedade, v. 27, n. 96, p. 1021-1056, 2006.

TRÓPIA, Patrícia Vieira. A Política para o ensino superior do Governo Lula: uma análise crítica. Cadernos da Pedagogia. UFSCar, Ano I, v. 2, p. 1-19, 2007.

TRÓPIA, Patrícia Vieira. O ensino superior em disputa: alianças de classe e apoio à política para o ensino superior no governo Lula. Revista Iberoamericana de Educación, v. 49, n. 3, p. 1-12, 2009. 